\title{
O PAPEL DA FOTOGRAFIA NA CONSTRUÇÃo SIMBÓlica DAS REFORMAS URBANAS. RIO DE JANEIRO, 1904-1906
}

The Role Of Photography In The Symbolic Construction Of Urban Reforms. Rio De Janeiro, 1904-1906

\section{Viviane Araujo}

Doutora em História Social da Cultura pelo Programa de Pós-Graduação da PUC-Rio vivianedasa@yahoo.com.br

\section{Resumo}

Este artigo analisa a fotografia como instrumento de documentação, publicização e legitimação das reformas urbanas ocorridas na cidade do Rio de Janeiro no início do século XX, com ênfase na abertura da Avenida Central (1904-1906). Ainda que o entendimento da fotografia como reprodução fiel e exata da realidade tenha justificado seu uso, a fotografia não só registrava, mas era utilizada pelo poder público para conferir significados sobre intervenções urbanas empreendidas naquele período. Desse modo, o artigo destaca a importância da fotografia na elaboração de imagens de grande valor simbólico, evidenciando a representação das reformas empreendidas no Rio de Janeiro como um caminho para o progresso brasileiro segundo os preceitos modernizadores da época, os quais atribuíam valoração positiva à derrubada do passado para a edificação de um futuro visto como progresso.

\section{Palavras chave}

Fotografia, reforma urbana, progresso

\section{Abstract}

This paper analyses the photography as instrument of documentation, publicizing and legitimacy of Rio de Janeiro's urban reforms at the early twentieth century, mainly opening the Avenida Central (1904-1906). Although the understanding of photography as a faithful and accurate reproduction of reality has justified its use, the photography not only recorded, but it was used by the government to confer meanings on urban interventions undertaken in that period. Thus, the article highlights the importance of photography in the processing of images of great symbolic value, showing the representation of the reforms undertaken in Rio de Janeiro as a way for the Brazilian progress against modernizers precepts of the time, 
which they attributed positive evaluation to the overthrow the past to build a future regarded as progress.

\section{Keywords}

Photography, urban reform, progress

\section{Fotografia e reforma urbana}

Desde a invenção da fotografia, na primeira metade do século XIX, a cidade tem sido um de seus enfoques temáticos mais recorrentes, sobretudo a partir dos desenvolvimentos tecnológicos que possibilitaram a ampliação dos usos e dos meios pelos quais estas imagens eram reproduzidas, multiplicando-se assim o número de observadores e a influência dessas imagens na conformação de noções a respeito das cidades retratadas. A imprensa ilustrada e os cartões-postais, que se proliferaram entre a passagem do século XIX para o XX, são exemplos dos meios pelos quais as imagens fotográficas se tornaram acessíveis a uma quantidade cada vez maior de pessoas. Com objetivos comerciais, fotógrafos e editores de álbuns, de postais e de diversos tipos de publicações ilustradas reproduziram imagens fotográficas, contribuindo para uma difusão cada vez mais ampla das cenas urbanas. Além disso, órgãos do poder público e empresas privadas responsáveis por construções de avenidas, espaços de circulação e lazer, pela ampliação dos transportes, do fornecimento de energia, etc., utilizaram a fotografia como forma de registrar, publicizar, conferir visibilidade e perenidade aos seus empreendimentos, construindo uma espécie de síntese a respeito do processo de transformação das cidades retratadas.

Pelo menos desde a década de 1980, os pesquisadores vêm se dedicando cada vez mais a compreender a história e os usos da fotografia na formação de imaginários urbanos no Brasil, destacando assim a importância das representações fotográficas para a conformação de noções a respeito das cidades, de seus habitantes, seus costumes, suas belezas e infortúnios. Em diferentes contextos históricos, atores sociais produziram, consumiram ou utilizaram imagens fotográficas e por meio delas elaboraram, mais ou menos conscientemente significados a respeito das realidades vividas. Assim, se o Rio de Janeiro dos fotógrafos Marc Ferrez e Augusto Malta, tal como analisam Ronaldo Entler e Antônio de Oliveira Jr. (2003), evidencia-se o contraste entre a cidade das elegantes fachadas que deveriam passar a representar a 
cidade moderna e a cidade dos cortiços insalubres que ratificavam as intervenções municipais; a cidade de São Paulo tal como analisada por Solange Ferraz de Lima e Vânia Carneiro de Carvalho (1997) apresenta em dois momentos históricos - o final do século XIX e a década de 1950 - formas diversas de representar um mesmo anseio: o progresso; já Charles Monteiro (2012) busca entender a própria formação de uma cultura visual por meio da análise das fotografias de Porto Alegre tal como veiculadas na imprensa em meados do século $X X$.

O desenvolvimento dos estudos sobre história e fotografia lança luz ainda a uma importante vertente da fotografia documental que permite ampliar as reflexões acerca das relações entre representação fotográfica e imaginários urbanos: o registro de reformas urbanas. A contratação de fotógrafos com a finalidade de documentar o desenvolvimento de reformas foi uma prática muito frequente desde a segunda metade do século XIX. Ao acompanhar o curso das obras, reproduzindo projetos e retratando os arquitetos e engenheiros responsáveis por estes, registrando o trabalho dos operários, os equipamentos utilizados, as cerimônias de inauguração e os aspectos gerais dos locais antes, durante e após a conclusão desses trabalhos de construção ou reforma, os fotógrafos atenderam à demanda de que tais intervenções fossem documentadas, a partir de um meio capaz de promover seu registro e divulgação da maneira considerada, então, a mais irrefutável de que se dispunha.

O uso da fotografia oferecia como vantagem em relação a outros modos de documentação a autenticidade que a sociedade em geral lhe atribuía, o que lhe garantia valor não somente como uma representação visual da realidade - isto é, como um artefato tridimensional criado para representar por meio de um espaço plástico bidimensional, uma porção da realidade visível -, mas como se esta fosse uma comprovação incontestável daquilo que apresenta em sua superfície visível. A encomenda de fotografias por gestores de obras públicas e privadas estava profundamente relacionada a esta crença depositada nas fotografias como registros fidedignos de uma dada realidade. Do mesmo modo, para os fotógrafos contratados, a realização dessas imagens deveria produzir uma documentação cabal e irrefutável, que atendesse às expectativas daqueles que Ihes encomendaram as imagens. Nesse sentido, é apropriado tomar como exemplo as seguintes palavras de Augusto Malta fotógrafo oficial da prefeitura do Rio de Janeiro de 1903 a 1936 - numa entrevista concedida ao jornal O Globo em 1936:

URBANA, V.6, no 9, ago-dez, 2014 - Dossiê: Dimensões Simbólicas das Intervenções Urbanas CIEC/UNICAMP 
Uma obra como aquela, um homem como aquele, não mereciam a falta de respeito de uma "tapeação". Entusiasmado, dediquei-me de corpo e alma à nova função. Diante do nada de fotografia que eu sabia, esforcei-me por conquistar o muito que agora sei. Embora uma função secundária e lateral, eu me orgulhava em dar a minha cooperação para a glória da grande obra. Ela precisava de uma documentação fiel e indiscutível que só as boas fotografias poderiam proporcionar. ${ }^{1}$

Com estas palavras, Malta explicitou seu entendimento acerca do papel por ele desempenhado, na condição de fotógrafo, junto às reformas urbanas empreendidas pela municipalidade do Rio de Janeiro, sob a gestão do prefeito Francisco Pereira Passos, entre 1902 e 1906. Em geral, as percepções da época enfatizavam a grande capacidade mimética da fotografia, percepção majoritária desde a invenção da fotografia, e que só seria maciçamente refutada cerca de um século mais tarde. Até a primeira metade do século $X X$, fosse para louvar as vantagens da nova técnica de produção de imagens ou para rejeitá-la como forma legítima de arte, a crença na fotografia como documentação "fiel e indiscutível" foi determinante tanto para os usos sociais $^{2}$ quanto para as reflexões intelectuais a respeito da fotografia.

Entretanto, não era apenas a precisão ou a riqueza de detalhes que levava a uma avaliação da fotografia como uma apreensão exata e indiscutível daquilo que apresentava em sua superfície visível, mas especialmente a ideia de que por meio do registro fotográfico haveria, para utilizar os termos de Andre Bazin, "uma transferência da realidade da coisa para a sua reprodução" (BAZIN, 1991, p. 22). Dito de outro modo, a crença na objetividade absoluta advinha da minimização do papel do operador da câmera enquanto um sujeito criador, ainda que este aparato devesse ser dirigido por fotógrafos competentes tecnicamente. Segundo o crítico francês, foi apenas a partir do advento da fotografia que, pela primeira vez, entre um objeto do mundo real e a sua representação nada se interpunha além de outro objeto e, por isso, afirmava "somos obrigados a crer na existência do objeto representado, literalmente re-presentado, quer dizer, tornado presente no tempo e no espaço" (BAZIN, 1991, p. 22). Este célebre texto de Bazin, publicado pela primeira vez em 1945 e intitulado "Ontologia da imagem fotográfica", evidencia ainda que tal apreensão não se limitou às primeiras décadas após a invenção da fotografia, mas que persistia mesmo um século mais tarde.

\footnotetext{
1 "Valiosa contribuição para o centenário de Pereira Passos: a obra do embelezador da cidade, documentada e contrastada pela fotografia". O Globo, 01 de agosto de 1936.

${ }^{2}$ Ver: FABRIS, Annateresa (org.) (1991). Fotografia: usos e funções no século XIX. São Paulo: EDUSP. URBANA, V.6, no 9, ago-dez, 2014 - Dossiê: Dimensões Simbólicas das Intervenções Urbanas CIEC/UNICAMP
} 
Todo um movimento de desconstrução/deslocamento da crença na credibilidade da imagem fotográfica foi operado a partir das críticas semiológicas da segunda metade do século $X X$, segundo as quais a sensação de "transferência" da realidade do objeto retratado para a sua reprodução foi designada como um "efeito", e que não passava de um instrumento de codificação do real, como a língua, por exemplo (DUBOIS, 1993, p. 36-44). Este empenho intelectual de desconstrução levou a uma reconsideração da crença na capacidade mimética, passando a entender a fotografia não como espelho do real, mas como representação carregada de valores que não são naturais, mas construídos historicamente segundo determinados preceitos culturais, sociais e estéticos. Por isso, as opções escolhidas pelo fotógrafo no momento da tomada - como a inclusão ou não de pessoas na cena e, em caso afirmativo, o uso ou não da pose, bem como a seleção e a relação dos elementos que serão enquadrados na cena -, assim como as escolhas posteriores, que podem ser tomadas por ele ou por quem utilize, para fins diversos, aquela fotografia - que envolvem, por exemplo, os meios de divulgação da imagem -, influenciam o produto final e a relação deste com seus futuros observadores.

É preciso estar atento também ao fato de que por meio da análise de aspectos plásticos tais como o enquadramento e a dinâmica entre os elementos dispostos na imagem, as cores, os planos, o tamanho e tipo de exposição a ser dada à fotografia, podemos dialogar com o fotógrafo e com os interlocutores para os quais produziu a imagem. Ainda que não seja possível "ver" a realidade passada como se a fotografia fosse uma espécie portal aberto diante de nossos olhos, podemos, através do exame de seus usos sociais, bem como de seus elementos plásticos centrais e secundários afinal, pode-se procurar no periférico e no imprevisto algo além daquilo que era o tema central das imagens - buscar compreender as relações políticas e sócio-culturais envolvidas na produção e circulação dessas imagens.

Sendo o ato de fotografar uma ação deliberada de registrar alguma coisa num universo amplo de possibilidades, observar o que foi fotografado e como foi fotografado permite analisar relações entre a fotografia e seu autor, a imagem e a sociedade, tanto num plano propriamente estético, a partir dos conteúdos plásticos da imagem fotográfica, quanto num plano social, ligado ao jogo político e cultural daqueles que a produziram e consumiram. Desse modo, para além de uma "ontologia", é necessário lidar com os contextos históricos, os atributos técnicos e estéticos e os usos sociais da representação fotográfica, bem como reconhecer as 
diferentes práticas que ao longo do tempo transformaram as percepções da fotografia no conjunto das representações visuais (cf. ROUILLÉ, 2009).

Para analisar o papel desempenhado pela fotografia como instrumento de documentação, publicização e legitimação das reformas urbanas, é importante considerar ainda o fato de que o intervalo de tempo no qual se desenvolveram obras que modificaram radicalmente a aparência e a função de locais que durante várias décadas haviam permanecido quase inalterados era relativamente curto e efêmero. Ainda que uma obra durasse alguns anos, tratava-se sempre de um tempo provisório, um período reconhecido como uma transição no caminho entre o passado e o futuro. Por isso, retratar este momento transitório, eternizá-lo através da fotografia, funcionava como uma maneira de inscrevê-lo na história da cidade, como um período, embora curto de tempo, de grande relevância simbólica.

Considerando-se que de acordo com o imaginário político e social das elites dirigentes da jovem república brasileira, o Rio de Janeiro - na condição de cidadecapital e de principal área mercantil e cosmopolita do país - era o locus principal da criação tanto material quanto ideal da modernidade brasileira, daí decorre a principal hipótese aqui defendida: ao se contratar fotógrafos a fim de registrar as reformas urbanas, as imagens produzidas deveriam apresentar visualmente etapas de um processo captado para que fosse entendido como uma demonstração de progresso. Tais fotografias deveriam contribuir para inscrever as transformações urbanas em um conjunto visual harmônico, representativo para aquela sociedade por seu conteúdo simbólico, social e estético.

De acordo com Jeffrey Needell (1993), a partir do último quartel do século XIX, o Rio de Janeiro havia se tornado um distrito de profissionais liberais, burocratas, empresários e estudantes, pessoas com amplo acesso ao pensamento e aos exemplos europeus e, com o advento da República, esta posição afirmou-se ainda mais. O porto do Rio era nesse período não só um grande importador de produtos industrializados destinados ao consumo da própria cidade, mas também da vasta área a qual abastecia. E, para atender às expectativas que foram depositadas sobre a capital da jovem república, parecia urgente a necessidade de substituir sua imagem de cidade atrasada, suja e pestilenta por uma que sugerisse conforto e segurança, que atrairiam a civilidade, os imigrantes, os avanços tecnológicos e os capitais desejados. A antiga cidade de ruas estreitas e tortuosas não correspondia às novas exigências.

URBANA, V.6, no 9, ago-dez, 2014 - Dossiê: Dimensões Simbólicas das Intervenções Urbanas CIEC/UNICAMP 
Não apenas por ser a sede do poder político nacional, mas em grande medida pela função simbólica da capitalidade ${ }^{3}$, o Rio de Janeiro deveria exercer a função de representar a nação. Para muitos observadores, tal função impunha importantes obrigações à cidade-capital em relação ao restante do país, sendo o seu caráter exemplar decisivo, fosse para o bem ou para o mal. Segundo as palavras expostas por Gonzaga Duque, numa crônica publicada na Kosmos, em fevereiro de 1905:

Quem diz França diz Paris, Londres é a Inglaterra, Berlim a Alemanha, como Viena é a Áustria. As capitais das nações têm, do mesmo modo que seus plenipotenciários, obrigações imprescindíveis. Se esses devem reunir as qualidades morais aos mais finos dotes do espírito para honrarem suas bandeiras, àquelas exigem-se aspecto e costumes que não humilhem seus povos. $^{4}$

Caberia à cidade dar o exemplo, para fora e para dentro, de que se caminhava rumo ao progresso, e de que seu povo não seria "humilhado" por aspectos e costumes que lhes desonrasse. Afirmação semelhante pode ser verificada no discurso de posse do presidente Rodrigues Alves, em 1902, quando este anunciou a reforma da capital brasileira como uma das grandes metas de seu governo, por considerá-la condição primordial para o desenvolvimento de todo o país:

Aos interesses da imigração aos quais depende em máxima parte o nosso desenvolvimento econômico, prende-se a necessidade de saneamento desta capital, trabalho sem dúvida difícil porque se filia a um conjunto de providências, a maior parte das quais de execução dispendiosa e demorada. É preciso que os poderes da República, a quem incumbe tão importante serviço, façam dele a sua mais séria e importante preocupação, aproveitando todos os elementos de que puderem dispor para que se inicie o caminho. A capital da República não pode continuar a ser apontada como sede de vida difícil, quando tem fartos elementos para constituir o mais notável centro de atração de braços, de atividades e de capitais nesta parte do mundo. ("O manifesto inaugural à nação". Correio da Manhã. 16 de novembro de 1902. Apud. Azevedo, 2003, p. 187)

Ao apresentar as obras de saneamento para o Rio de Janeiro, Rodrigues Alves referiu-se aos interesses de desenvolvimento sócio-econômico, como a atração de

\footnotetext{
${ }_{3}^{3}$ Para uma análise do conceito de capitalidade na história do Rio de Janeiro, ver os artigos: AZEVEDO, André Nunes de. "A capitalidade do Rio de Janeiro: um exercício de reflexão histórica" e RODRIGUES, Antônio Edmilson M., "Em algum lugar do passado: cultura e história na cidade do Rio de Janeiro". Ambos publicados em: AZEVEDO, André Nunes de (org.) (2002). Anais do Seminário Rio de Janeiro: capital e capitalidade. Departamento Cultural/ NAPE/DEPEXT/ UERJ.

${ }^{4}$ Gonzaga Duque. "A queda dos muros - a rua Sete de Setembro". Kosmos, fevereiro de 1905. URBANA, V.6, no 9, ago-dez, 2014 - Dossiê: Dimensões Simbólicas das Intervenções Urbanas CIEC/UNICAMP
} 
atividades produtivas, de trabalhadores imigrantes e de capitais internacionais. A reforma do porto e a construção de três grandes avenidas destinadas a facilitar a comunicação entre a região portuária e diversos pontos da cidade foram empreendimentos que ficaram a cargo da administração federal. Sob o comando do Ministro da Indústria, Comércio, Viação e Obras Públicas, Lauro Müller, foram construídas a Avenida Central - rebatizada, em 1912, como Avenida Rio Branco -, que ligaria o porto à cidade velha e à zona sul; e as avenidas do Cais, - atual Rodrigues Alves -, e do Mangue - hoje, Francisco Bicalho -, que facilitariam o acesso a bairros como São Cristóvão e Caju. Para comandar a Diretoria Geral de Saúde Pública, foi nomeado o médico sanitarista Oswaldo Cruz. O engenheiro Francisco Pereira Passos foi o escolhido pelo presidente para assumir a prefeitura do Rio de Janeiro.

As medidas tomadas em prol da modernização viária, do embelezamento e da melhoria das condições sanitárias, que envolviam a reforma do porto, a abertura de avenidas, a ampliação das redes de água potável e esgoto, bem como de iluminação e transporte, a normatização das condições de higiene das moradias coletivas e da distribuição de alimentos, entre outras medidas, importavam tanto quanto a construção simbólica de uma imagem moderna e civilizada para a cidade por meio de representações culturais, inclusive, de fotografias, como veremos a seguir. A partir do entendimento do próprio tempo como um período de transição, os empreendimentos de cunho modernizador eram impulsionados pela consciência de que a construção do Rio de Janeiro de princípios do século XX como uma cidade moderna assentava-se sobre a busca de algo que não se tinha no presente, mas que se vislumbrava em relação ao futuro, segundo uma percepção do tempo moderno como um tempo que se opunha a um passado que se pretendia superar.

\section{A construção a partir dos escombros nas fotografias da abertura da Avenida Central}

A região central da cidade do Rio de Janeiro era vista na passagem do século XIX para o XX como o foco dos miasmas que assolavam a população, tais como a febre amarela, a peste bubônica e a tuberculose. A alta concentração populacional no antigo centro, a precária rede de abastecimento de água e saneamento, os cortiços superlotados, as ruas estreitas comprimidas entre morros que, segundo médicos sanitaristas, impediam a chegada dos ventos saudáveis vindos do oceano até o

URBANA, V.6, no 9, ago-dez, 2014 - Dossiê: Dimensões Simbólicas das Intervenções Urbanas CIEC/UNICAMP 
coração da cidade eram algumas das características que conferiam à cidade uma impressão de atraso no caminho em direção ao progresso.

A realização de uma grande reforma na região central da cidade, que incluísse a abertura de uma ampla avenida capaz de canalizar os ventos oceânicos da Baía de Guanabara era um projeto que já vinha sendo almejado pelo menos desde a década de 1870, embora apenas a partir da passagem para o século XX tal projeto se tornaria uma realidade tangível. Mas, já naquela ocasião - ainda que os planos apresentados nos dois relatórios produzidos pela Comissão de Melhoramentos da Cidade do Rio de Janeiro, em 1875 e 1876, tenham recebido duras críticas e por isso não chegaram a sair do papel - a construção de avenidas amplas aparecia como uma necessidade imprescindível para as cidades modernas:

\begin{abstract}
Entre os povos bárbaros, e entre outros adiantados em civilização, as ruas são igualmente acanhadas e mal dispostas. O mesmo defeito ainda se nota em quase todas as cidades da Europa, que não têm sofrido alterações no século presente. É que os nossos antepassados não sentiam as necessidades que têm criado a civilização moderna, para satisfazer as quais é necessário aumentar a largura das ruas. Assim, os novos Boulevares de Paris, Ringstrasse em Viena, as ruas dos novos quarteirões em Londres, a avenida da Pensilvânia em Washington têm larguras que em alguns casos vão além de quarenta metros" (Primeiro relatório, 1875. Apud. AZEVEDO, 2003, p. 214-5)
\end{abstract}

Até 1902, quando Rodrigues Alves anunciou a reforma da então Capital Federal como uma das principais metas de seu governo, tais proposições ganhavam cada vez mais força e justificavam intervenções drásticas. Numa cidade com a configuração espacial do Rio de Janeiro, as ruas estreitas e sinuosas, localizadas numa região altamente acidentada, eram apontadas como causas das dificuldades tanto da circulação de ar, quanto de veículos e mercadorias. A partir da defesa da rua reta e da avenida larga, chegou-se a apelar para a noção de que retificar as vias exerceria influência até mesmo no caráter da população.

Acostumados desde a infância com as ruas estreitas, escuras e tortuosas do Rio de Janeiro, o carioca é um defeituoso, não enxerga bem e caminha mal; coloque-o em uma rua movimentada de Berlim em que há o hábito das direções certas de subida e descida no passeio das ruas e ele esbarrará a cada passo, acotovelando os transeuntes.

E como todos os efeitos têm a sua causa primordial, eu ainda repito: a influência da linha reta no moral e no físico do homem, não é uma ficção; a reta não é só o caminho por onde a luz se propaga e difunde para chegar aos nossos olhos, é também o caminho por onde a luz chega ao nosso espírito; e a prova é, que a linha reta do dever é um fato moral. (Discurso do engenheiro URBANA, V.6, no 9, ago-dez, 2014 - Dossiê: Dimensões Simbólicas das Intervenções Urbanas CIEC/UNICAMP 
Augusto Liberalli. Revista do Clube de Engenharia. Fevereiro de 1901. Rio de Janeiro: Imprensa Nacional, 1901. pp. 176-177. Apud. AZEVEDO, 2003, p. 163)

A abertura da Avenida Central - rebatizada, em 1912, como Avenida Rio Branco, em homenagem ao recém-falecido Ministro das Relações Exteriores - era, para seus defensores, o símbolo máximo dessa perspectiva de progresso material e espiritual, "símbolo e realidade ao mesmo tempo" (FABRIS, 2000, p. 18). Os antigos espaços destruídos, bem como as novas construções que compunham o bulevar, ao mesmo tempo em que remetiam a uma realidade materialmente concreta - indicando os avanços técnicos da construção civil e o gosto arquitetônico de cada edifício, cada poste de iluminação, cada árvore ali disposta - apontavam para os próprios trabalhos de destruição e construção com um forte componente simbólico: a passagem do "colonial" ao "cosmopolita".

O bulevar começou a ser aberto em 28 de fevereiro de 1904, sendo as primeiras demolições realizadas na Rua da Prainha - atual Acre, nas proximidades da região portuária, extremidade norte da avenida. Poucos dias mais tarde, no dia 08 de março do mesmo ano, foi feita naquele mesmo local uma espécie de festa de inauguração das obras, que contou com a presença de membros da Comissão Construtora da Avenida Central, políticos, engenheiros, operários e quem mais quisesse acompanhar a cerimônia. Segundo um artigo publicado no dia seguinte à comemoração na Gazeta de Notícias (Apud. KOK, 2005, p. 78), o presidente da República, Rodrigues Alves, e o Ministro da Indústria, Comércio, Viação e Obras Públicas, Lauro Müller, ligaram o motor de um perfurador e manejaram a máquina por alguns instantes, contra a parede próxima ao local onde foram dispostas as várias bandeiras que podemos ver no canto esquerdo da fotografia a seguir [figura 1].

URBANA, V.6, no 9, ago-dez, 2014 - Dossiê: Dimensões Simbólicas das Intervenções Urbanas CIEC/UNICAMP 


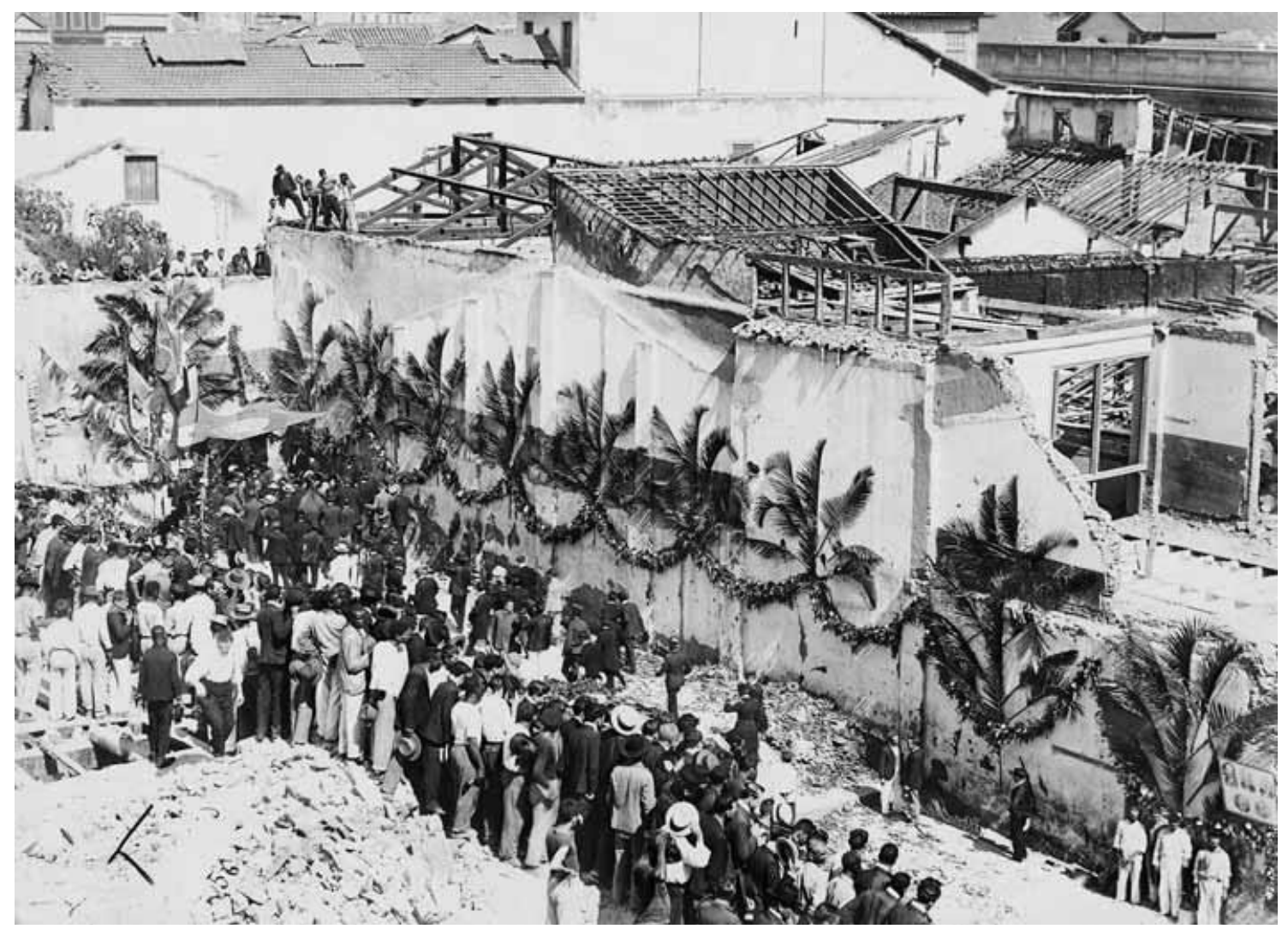

Figura 1 - Cerimônia de abertura dos trabalhos de construção da Avenida Central, Fonte: João Martins Torres, 1904

Na cena, podemos ver a realização da cerimônia em meio a pilhas de entulhos e edifícios de alvenaria parcialmente demolidos; os adornos feitos com guirlandas de flores e ramos de coqueiros que enfeitaram um muro já afetado pela obra; além de algumas dezenas de pessoas que, sobre montes de escombros e muros ainda de pé, observavam as autoridades federais que dirigiam a solenidade. Contudo, a maior parte da imagem é ocupada pelos restos de materiais dos prédios que vinham sendo derrubados, com suas estruturas de madeira expostas pelo destelhamento e suas paredes de tijolos quebradas. De modo que a solenidade dirigida pelas autoridades públicas, ainda que figure no centro da imagem, não tem seus detalhes facilmente identificados ao observarmos a cena. A partir do ponto de vista e do enquadramento adotados pelo fotógrafo, a inclusão no conjunto da imagem de todo esse ambiente em processo de demolição, torna o próprio cenário das demolições tão protagonista dessa fotografia quanto a realização da cerimônia inaugural.

Esta foi uma das primeiras fotografias de uma série de imagens do processo de abertura da Avenida Central produzida por João Martins Torres, que registrou as diversas etapas de construção do novo bulevar, desde as primeiras demolições até a construção dos novos edifícios e as festividades oficiais de inauguração - além da URBANA, V.6, no 9, ago-dez, 2014 - Dossiê: Dimensões Simbólicas das Intervenções Urbanas CIEC/UNICAMP 
cerimônia de início dos trabalhos, que vimos na foto acima, foram realizadas ainda outras duas inaugurações: a do eixo da Avenida, em 07 de setembro de 1904, e a sua inauguração final, ainda que grande parte dos edifícios permanecesse ainda em fase de construção, em 15 de novembro de 1905. Tais imagens pertencem ao acervo particular deixado pelo engenheiro Paulo de Frontin, que dirigiu a Comissão Construtora da Avenida Central, subordinada ao Ministério da Indústria, Comércio, Viação e Obras Públicas, chefiado por Lauro Müller. De acordo com Maria Inez Turazzi (2006), a presença dessas fotografias no arquivo privado de descendentes do engenheiro pode levantar a hipótese de que elas tenham sido encomendadas pela comissão chefiada por Frontin, ainda que o nome de João Martins Torres não seja muito conhecido na história da fotografia do Rio de Janeiro, e que estas imagens não tenham configurado um álbum, tal como o que foi encarregado a Marc Ferrez pela mesma comissão.

Além de Torres e de Ferrez, Augusto Malta também registrou determinadas etapas de abertura do bulevar e construção de alguns edifícios, mas a maior parte de suas fotografias captou a avenida já completamente aberta ao trânsito de pessoas e veículos, concentrando-se nas formas de utilização daquele novo espaço de negócios e lazer pelos citadinos. O registro do planejamento e do gosto arquitetônico dos novos edifícios ficou a cabo de Marc Ferrez, contratado para produzir o Álbum da Avenida Central, concluído em $1907^{5}$, composto por pranchas impressas em fotogravura. Nesse álbum, os projetos desenhados para as fachadas dos novos prédios - que precisaram ser aprovadas pelo que se tornou conhecido como "concurso de fachadas" - foram reproduzidos e apresentados ao lado da fotografia do mesmo edifício [figura 2], caso a construção do prédio estivesse concluída. Os prédios que permaneciam em fase de construção não foram fotografados, nesse caso, apenas as plantas das fachadas figuraram em suas pranchas. Já as fotografias de João Martins Torres chamam a atenção sobretudo pela maneira que expõem a execução das obras, caracterizando-se como imagens dramáticas e poeirentas, cujas composições visuais frequentemente priorizaram o espetáculo da destruição da cidade velha [figura 3].

\footnotetext{
${ }^{5} \mathrm{O}$ exemplar consultado para esta pesquisa foi a edição comemorativa produzida pela Ex-Libris em 1983. O álbum original tinha como capa um estojo revestido de tecido verde escuro, e não trazia o mesmo nome usado nessa edição comemorativa - Álbum da Avenida Central - mas as seguintes palavras gravadas em letras douradas, "Avenida Central - 8 de março de 1903 - 15 de novembro de 1906 - Marc Ferrez - Rio de Janeiro".

URBANA, V.6, no 9, ago-dez, 2014 - Dossiê: Dimensões Simbólicas das Intervenções Urbanas CIEC/UNICAMP
} 

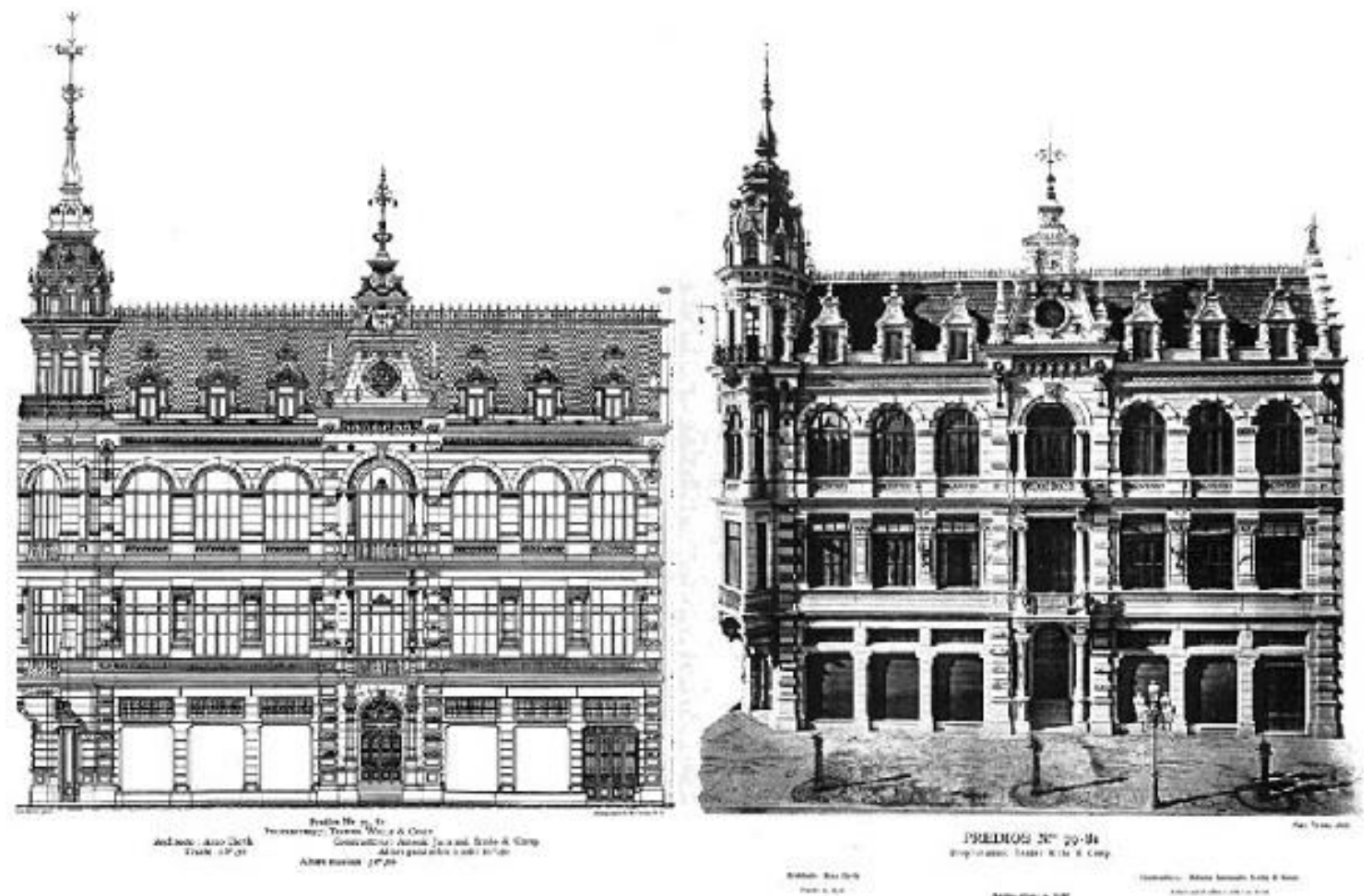

Figura 2 - Projeto da fachada e sua fotografia correspondente Fonte: Marc Ferrez, c.1905

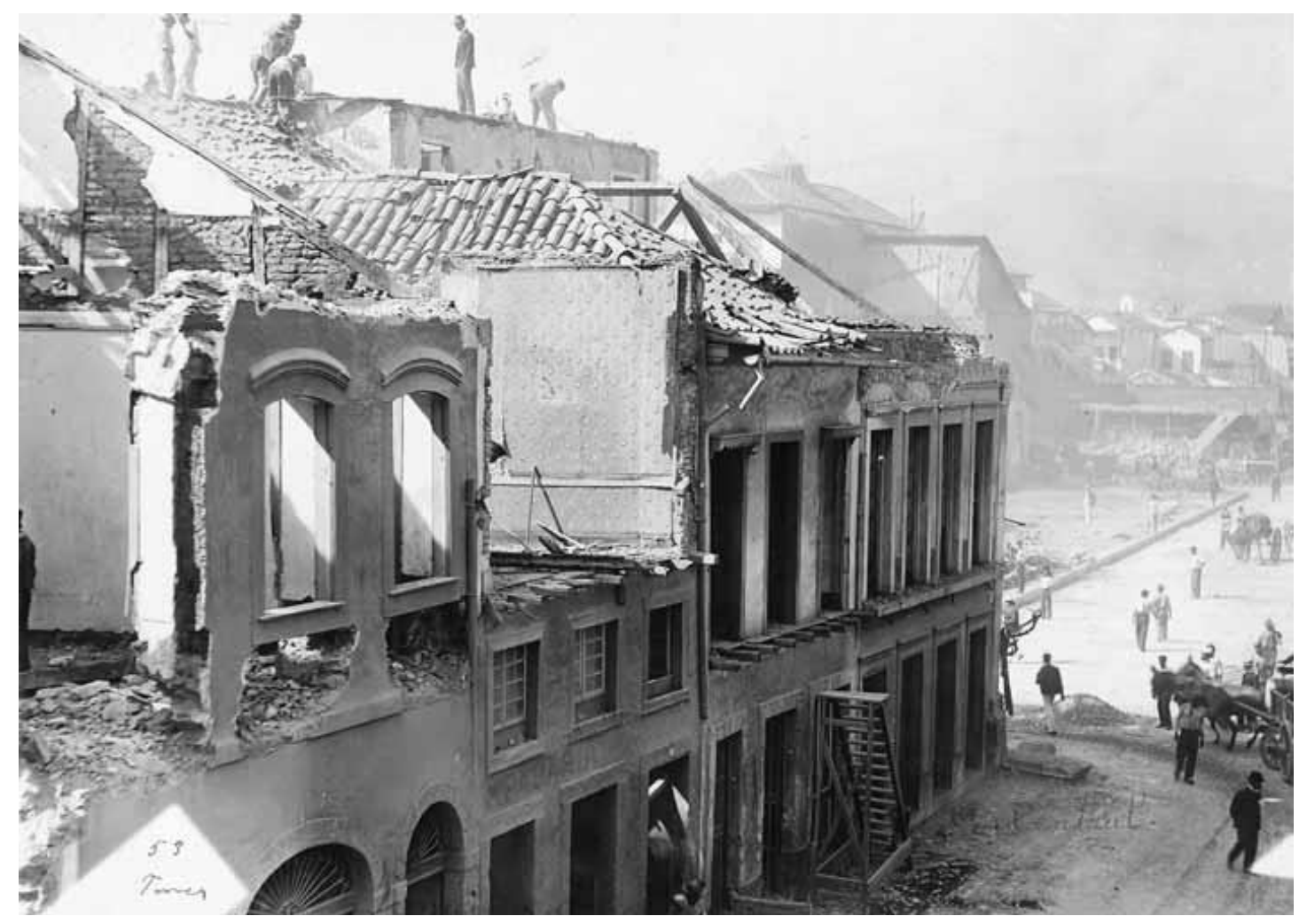

Figura 3 - Demolições para a abertura da Avenida Central Fonte: João Martins Torres, c.1904-5

URBANA, V.6, no 9, ago-dez, 2014 - Dossiê: Dimensões Simbólicas das Intervenções Urbanas CIEC/UNICAMP 
Ao fotografar os prédios construídos na Avenida Central entre 1904 e 1906, Ferrez deixou fora do espaço plástico elementos que compunham o espaço real observado, tais como o entulho, os andaimes e os operários que trabalhavam nas edificações; abrangendo na imagem somente as fachadas dos edifícios, recortados do ambiente ao redor, incluindo geralmente apenas a calçada adiante e, raramente, algum transeunte. Torres também procedeu a tarefa de selecionar, recortar e dispor no visor de sua câmera os elementos que comporiam o espaço plástico de suas fotografias, numa operação simultânea de incluir e excluir, ainda que este pareça ter abarcado dados do ambiente potencialmente dispensáveis se levarmos em conta o tema central de algumas dessas fotografias - um exemplo é a imagem da cerimônia de inauguração dos trabalhos de demolição que vimos anteriormente [figura 1], que trazia uma série de elementos periféricos à cerimônia propriamente dita.

Já nas fotografias que registram o andamento das obras de demolição, do recolhimento de entulho e da construção dos novos edifícios, o cenário da transformação em curso se apresenta, ela mesma, como o tema central das imagens. De modo que não eram somente as ruínas do que se punha abaixo que despertavam o interesse nessas imagens, mas o que elas apontavam sobre o processo de construção da nova cidade. Não por acaso, aparecem publicadas na imprensa carioca desde período diversas fotografias com conteúdo semelhante às produzidas por João Martins Torres, para as quais as cenas de trabalhos de desmontagem e arrasamento serviam como tema central [figura 4]. Para os entusiastas da reforma urbana, a substituição dos antigos prédios a fim de dar lugar ao novo bulevar expressava a vitória sobre aquilo que viam como exemplo do passado, do atraso, das tradições tidas como anacrônicas e obsoletas. Como afirma Olavo Bilac na "Chronica", publicada na revista Kosmos no momento em que obras de abertura da Avenida Central foram iniciadas:

No aluir das paredes, no ruir das pedras, no esfarelar do barro, havia um longo gemido. Era o gemido soturno e lamentoso do Passado, do Atraso, do Opróbrio. A cidade colonial, imunda, retrógrada, emperrada nas suas velhas tradições, estava soluçando no soluçar daqueles apodrecidos materiais que desabavam. Mas o hino claro das picaretas abafava esse protesto impotente. Com que alegria cantavam elas, as picaretas regeneradoras! E como a alma dos que ali estavam compreendiam bem o que elas diziam, no seu clamor incessante e rítmico, celebrando a vitória da higiene, do bom gosto e da arte! ${ }^{6}$

\footnotetext{
${ }^{6}$ Olavo Bilac. "Chronica". Kosmos, março de 1904.

URBANA, V.6, no 9, ago-dez, 2014 - Dossiê: Dimensões Simbólicas das Intervenções Urbanas CIEC/UNICAMP
} 


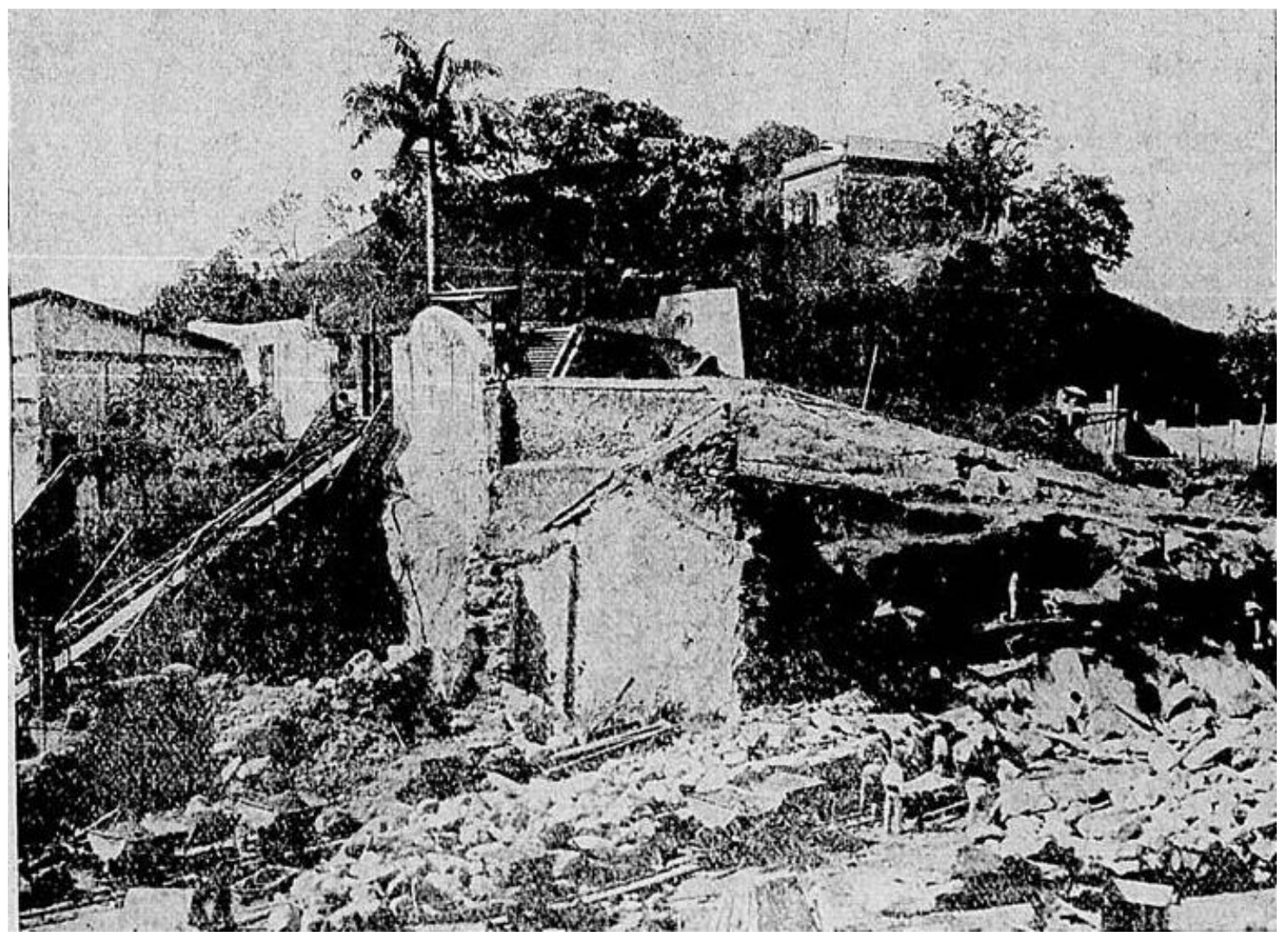

Figura 4 - Parte do morro de São Bento sendo derrubada para a abertura da Avenida Central Fonte: Fotografia publicada na Revista da Semana em 10 de julho de 1904, autor não identificado

Tais imagens captam e eternizam aquele momento no qual as modificações empreendidas elaboravam um jogo de oposições que era entendido não somente como um progresso estético, mas ético. Visto que a condução da modernidade fundamentada a partir da reforma urbana, defendia o arrasamento do velho como condição fundamental para a construção do novo. Isto é, partia do pressuposto de que o alargamento e retificação de ruas, o saneamento e a iluminação públicas eram muito mais do que obras de construção civil, pois a ideia de condução da modernidade fundamentada na reforma urbana, pressupunha igualmente que o arrasamento do que anteriormente estava estabelecido se apresentava como condição necessária para a construção do novo. Isto quer dizer que, no percurso vivido na direção do progresso, tão importante quanto erguer seria pôr abaixo.

O interesse em registrar a trajetória temporal da reforma fica claro quando observarmos a existência, no interior da própria série, de fotografias que captaram diferentes fases da obra em um mesmo local. Tomadas a partir de pontos de vista bastante semelhantes, estas imagens formam uma espécie de narrativa que segue o curso da reforma, tal como vemos nestas fotografias que mostram a abertura da URBANA, V.6, no 9, ago-dez, 2014 - Dossiê: Dimensões Simbólicas das Intervenções Urbanas CIEC/UNICAMP 
extremidade sul da avenida, local onde atualmente está situada a Praça Floriano, na região conhecida como Cinelândia [figuras 5 e 6]. Alguns elementos presentes nas duas imagens situam a localização, como a paisagem da Baía de Guanabara, com o Pão de Açúcar ao fundo, e o Convento da Ajuda, à direita nas imagens, construção que a princípio foi mantida, mas que em 1911 também acabou sendo derrubada.

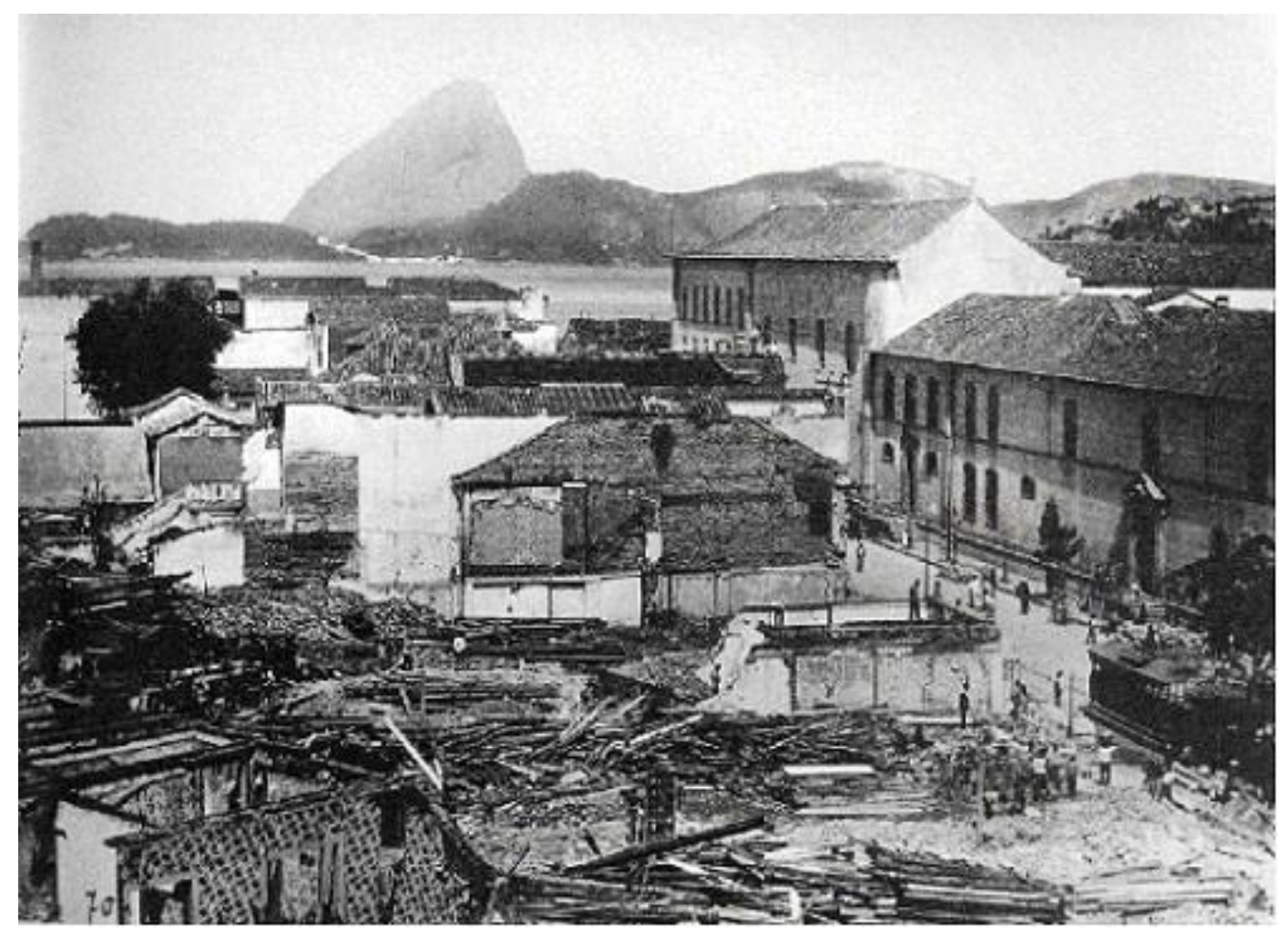

Figura 5 - Demolições nas proximidades do Convento da Ajuda [atual Cinelândia], Fonte: João Martins Torres, 1904-05 


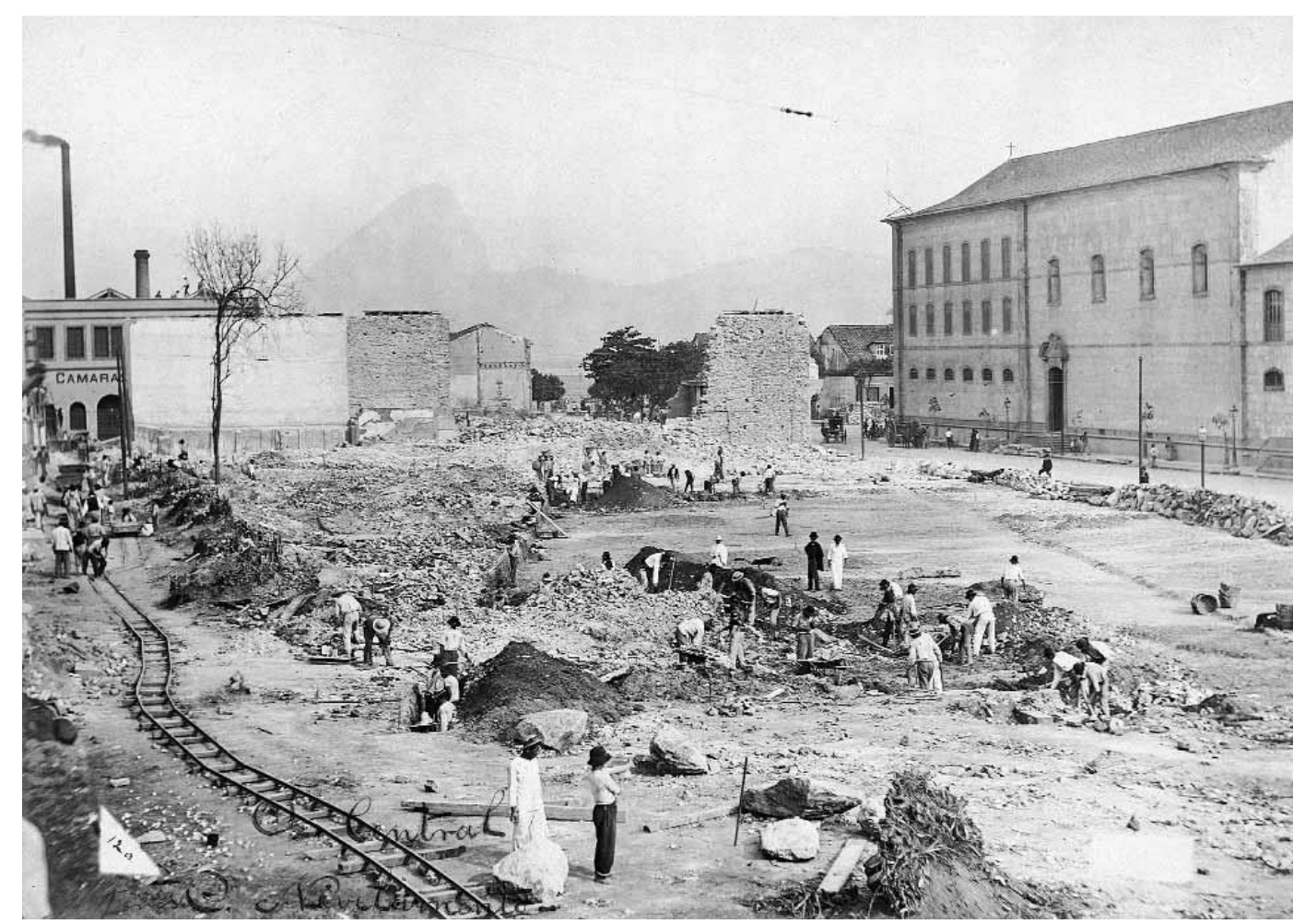

Figura 6 - Remoção de entulho nas proximidades do Convento da Ajuda [atual Cinelândia] Fonte: João Martins Torres, 1905

Pode-se dizer que os espaços registrados por João Martins Torres durante as obras são efêmeros e transitórios. A cidade em ruínas e a cidade em construção, registradas por Torres, são efêmeras porque localizadas num tempo distinto do antes - a cidade "colonial" - e do depois - a metrópole "afrancesada" que aquele projeto de reforma operava. O novo Rio de Janeiro, projetado pelas autoridades municipais e federais, parecia nascer de um corte, rápido, violento, a partir de obras que num curto intervalo de tempo tornariam aqueles espaços urbanos irreconhecíveis. Tais fotografias captaram paisagens urbanas com as quais os moradores da cidade conviveriam apenas por um intervalo muito curto de tempo. A imagem que mostra a passagem de um bonde elétrico no caminho já aberto pelas obras de construção da avenida [figura 7], por exemplo, registra a linha de bonde que foi instalada pela Companhia Jardim Botânico após as primeiras demolições, a fim de auxiliar o transporte de materiais de construção e trabalhadores, mas que foi desativada logo que o trabalho de abertura da avenida foi concluído. Por isso, o que a imagem eternizou foi um aspecto da paisagem urbana que durou muito pouco. Vale lembrar, nesse sentido, a observação de Philippe Dubois a respeito do corte temporal operado pela fotografia: 
se o ato fotográfico reduz o fio do tempo a um ponto, se faz da duração que escoa infinitamente um simples instante detido, não é menos claro que esse simples ponto, esse lapso curto, esse momento único, levantado do contínuo do tempo referencial, torna-se, uma vez pego, um instante perpétuo: uma fração de segundo, decerto, mas "eternizada", captada de uma vez por todas, destinada (também) a durar, mas no próprio estado em que ela foi captada e cortada. (DUBOIS, 1993, p. 168) [Grifos do autor]

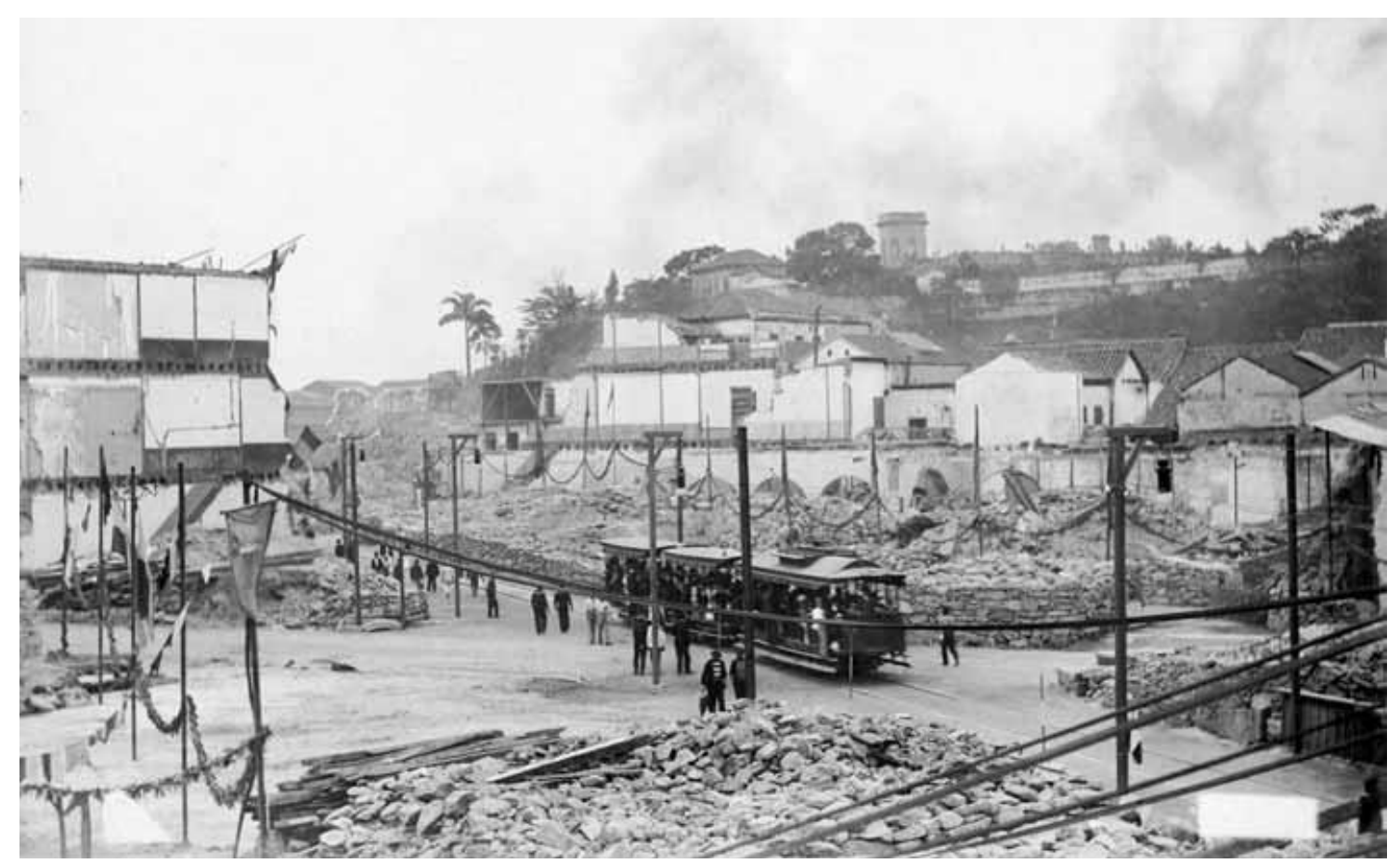

Figura 7 - Demolições e linha de bonde instalada durante a construção da Avenida Central Fonte; João Martins Torres, 1904-5

Contudo, mesmo em imagens de trabalhos de construção mais adiantados, alguns restos de prédios derrubados, o entulho gerado pelas demolições, bem como as tábuas de madeiras e andaimes que escondiam parcialmente as fachadas dos edifícios, e os operários que ali trabalhavam cobertos de poeira, ainda se faziam presentes nas fotografias de Torres. Mesmo que tais elementos pudessem ser avaliados como empecilhos à visualização dos prédios que vinham sendo construídos, como podemos ver num artigo publicado n'O Malho, em 28 de janeiro de 1905:

Pois não é sonho, não, senhores! A grande Avenida Central, projetada e rasgada, de lado a lado, do Boqueirão do Passeio à Prainha, já ostenta grande número de construções, especialmente no trecho entre a Rua do Hospício e o Largo da Mãe do Bispo. Casas comerciais de primeira ordem, redações de jornais diários, Municipalidade, clubes e associações, todos à porfia, estão levantando os novos edifícios onde passarão a funcionar dentro em pouco. Brilhantes espécimes de arquitetura já se observam ao longo da grande via, 
uns ainda em simples esqueletos, outros já revestidos da mão de obra que pronuncia a próxima terminação.

Ainda é cedo para aquilatar do valor e do gosto de tais construções, porque os andaimes ou prejudicam muito ou obstam por completo a visada do observador. Uma coisa entretanto, se pode desde já afiançar: é a solidez com que vão sendo feitas de acordo com a longa experiência dos construtores e a natureza do subsolo que vai se revelando no decurso das escavações. O que se está fazendo não é obra de fancaria, nem objeto de peschisbeque: é arquitetura airosa, sóbria, elegante e duradoura. ("As construções na Avenida". Apud. BRENNA, p. 310)

Ainda que estas palavras defendessem que ainda era "cedo para aquilatar do valor e do gosto de tais construções, porque os andaimes ou prejudicam muito ou obstam por completo a visada do observador", percebe-se que a construção dos edifícios tinha um lugar privilegiado na imaginação sobre o futuro ocupado pela nova avenida na paisagem urbana. A solidez e o bom gosto era algo que já se podia prever mesmo que muitas edificações ainda estivessem em fase de "simples esqueletos". De modo que as fotografias da Avenida em construção poderiam funcionar como uma espécie de metonímia da transformação da própria cidade: observava-se, passo a passo, o velho sendo destruído e o novo, erguido.

Até mesmo a partir de amplos planos, que mostraram o bulevar já com seus postes de iluminação dispostos nas calçadas e nos pequenos canteiros centrais, bem como a construção dos novos prédios, estes compartilhavam o espaço plástico com diversos tipos de materiais de construção. A paisagem ao redor coloca até mesmo edifícios já quase totalmente concluídos em meio a um cenário de obras, ainda que tal edifício assumisse o centro da imagem, como no caso da fotografia que retrata a Avenida Central na esquina com a Sete de Setembro, tomada na direção da Praça Mauá, na qual Torres registrou a sede do jornal O Paiz na porção central da cena [figura 8]. Enquanto nas imagens produzidas por Ferrez houve um grande cuidado em retratar os edifícios perfeitamente "limpos", destacados do fundo e livres dos andaimes, tábuas e entulho que foram elementos marcantes nas fotografias de Torres, este parece ter feito questão de retratar o clima de transitoriedade que caracterizava o momento da reforma daquele espaço.

URBANA, V.6, no 9, ago-dez, 2014 - Dossiê: Dimensões Simbólicas das Intervenções Urbanas CIEC/UNICAMP 


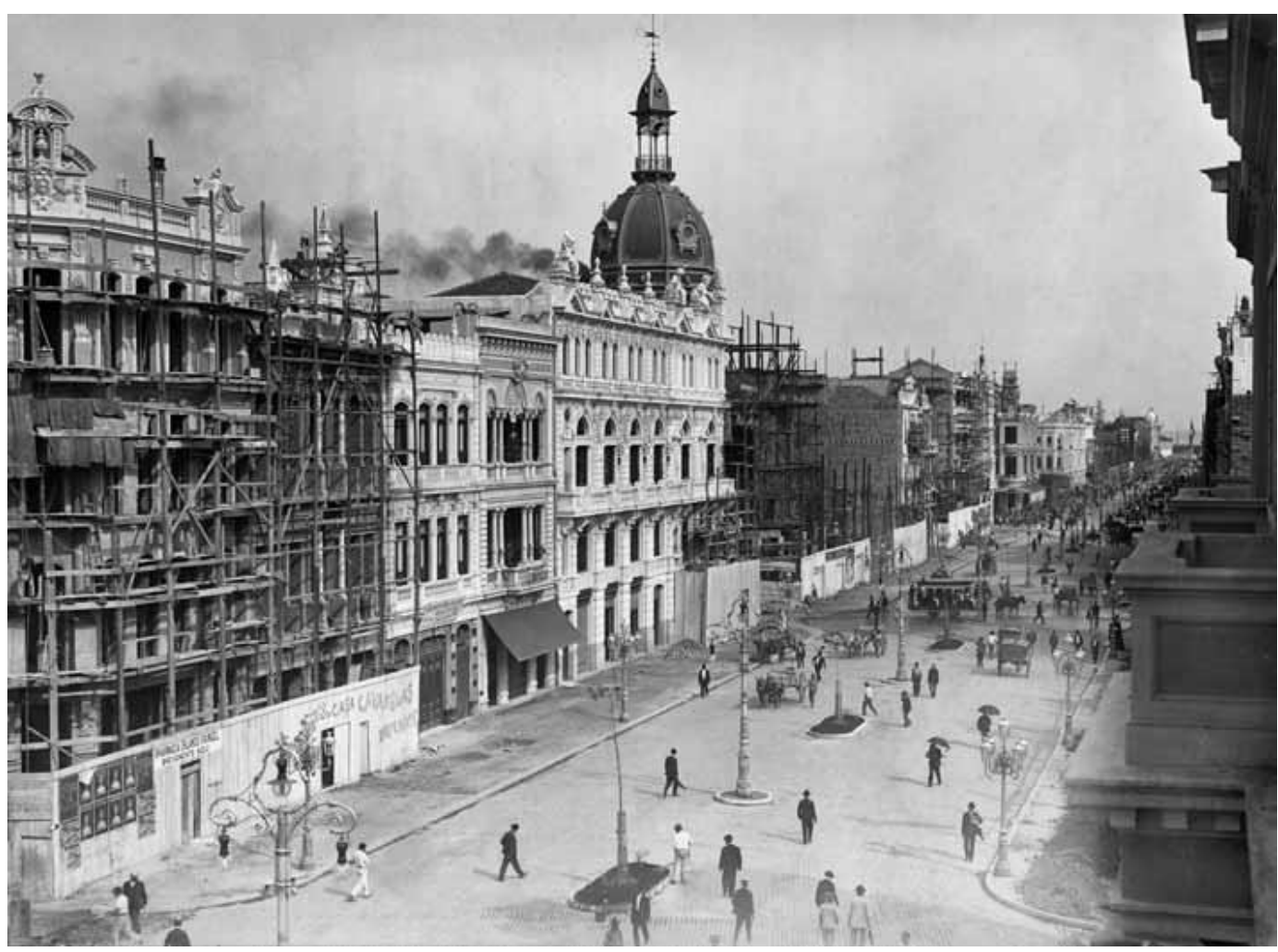

Figura 8 - Novos edifícios da Avenida Central já em construção

Fonte: João Martins Torres, 1905-06

\section{Considerações finais}

Toda fotografia se caracteriza pela suspensão do tempo, a partir de um gesto que efetua um corte não apenas de determinada porção do espaço observado, como também do tempo, afinal, este segue transcorrendo depois da realização da tomada que eternizou aquele instante. Tendo em vista essa característica própria da imagem fotográfica, é interessante perceber que ao observar a fachada de um edifício da Avenida Central registrada por Marc Ferrez, vemos imagens que eternizaram determinados espaços como se estes fossem eternos. Ao deixar de registrar junto ao tema central praticamente qualquer tipo de elemento periférico, Ferrez mostrava os edifícios fotografados de modo que estas fotos se diferenciassem o mínimo possível dos projetos desenhados pelos arquitetos. Por outro lado, ainda que $o$ ato de eternizar o temporário seja parte da essência da fotografia, as imagens de João Martins Torres não apresentam o corte temporal somente como um dado subjacente a toda fotografia, mas como o seu objetivo central, como o seu próprio tema. Assim, o efeito de tornar perpétuo o passageiro é multiplicado em suas fotografias da construção da Avenida Central. E não somente porque essas fotos foram tomadas num momento em que as reformas ainda estavam sendo realizadas e prosseguiriam seguindo o seu curso mas, principalmente, pelo fato de que tais fotografias registravam cenas nas URBANA, V.6, no 9, ago-dez, 2014 - Dossiê: Dimensões Simbólicas das Intervenções Urbanas CIEC/UNICAMP 
quais a tensão temporal estava explícita nas próprias imagens. Tensão decorrente do fato de que nas fotografias de Torres, as ruínas do passado e as novas construções compartilhavam a mesma cena, coincidindo espacial e temporalmente. Representada dessa maneira, a transição operada pela reforma urbana, quando fotografada, evidenciava, ao mesmo tempo, o antes e o depois, apresentando o presente como o tempo efêmero em que o passado começa a dar lugar ao futuro.

Embora efêmero, o tempo no qual as reformas urbanas eram vividas possuía uma grande relevância simbólica, pois tornava visível uma noção específica de transição: uma noção que entendia o futuro como progresso, como superação do passado. Modernizar a cidade, portanto, não remetia somente à solução de problemas tais como as condições de salubridade, a eficiência do porto ou a circulação de pessoas e veículos numa cidade que vivia um grande crescimento demográfico, mas visavam promover uma vida moderna, próspera e civilizada. Isto é, visavam a transformação do antigo Rio de Janeiro de feições "coloniais" na moderna capital cosmopolita almejada pelas elites políticas que buscaram dirigir estas transformações, bem como por intelectuais e setores médios que viram nestas reformas mais do que uma transformação do meio físico, mas um caminho para a transformação moral da sociedade. A percepção da cidade como o locus por excelência do desenvolvimento da modernidade nacional, levou à elaboração tanto de intervenções físicas, por meio de reformas, quanto de representações culturais que dessem sentido às transformações vividas, entre as quais aqui se buscou destacar o papel da fotografia, instrumento de documentação que teve uma função importante não somente para o registro das várias etapas das obras, mas para a elaboração de imagens de grande valor simbólico para o seu tempo, ao corroborar a noção de futuro como progresso e do tempo das reformas urbanas como seu marco decisivo.

\section{Referências}

ARCARI, Antonio (1983). A fotografia: as formas, os objetos, o homem. Lisboa: Edições 70.

ARNHEIM, Rudolf (2001). O poder do centro. Lisboa: Edições 70.

AUMONT, Jacques (1995). A imagem. Campinas: Papirus.

AZEVEDO, André Nunes de (2003). Da Monarquia à República: um estudo dos conceitos de Civilização e Progresso na cidade do Rio de Janeiro entre 1868 e 1906. Tese de Doutorado. Pontifícia Universidade Católica do Rio de Janeiro. História Social da Cultura.

URBANA, V.6, no 9, ago-dez, 2014 - Dossiê: Dimensões Simbólicas das Intervenções Urbanas CIEC/UNICAMP 
BARTHES, Roland (1984). A câmara clara. Rio de Janeiro: Nova Fronteira.

BARTHES, Roland (1990). O óbvio e o obtuso. Ensaios críticos III. Rio de Janeiro: Nova Fronteira.

BAZIN, André (1991). "Ontologia da imagem fotográfica". In: O cinema. Ensaios. São Paulo: Editora Brasiliense.

BELLAVANCE, Guy (1997). "Mentalidade Urbana, mentalidade fotográfica". In: PEIXOTO, Clarice E.; MONTE-MÓR, Patrícia (editores). Cadernos de Antropologia e Imagem: A Cidade em Imagens. Rio de Janeiro: UERJ / Núcleo de Antropologia e Imagem (NAI), $\mathrm{n}^{\circ} 4$.

BENCHIMOL, Jaime Larry (1992). Pereira Passos: um Haussmann tropical. A renovação urbana da cidade do Rio de Janeiro no início do século XX. Rio de Janeiro: Biblioteca Carioca.

BRenNA, Giovanna Rosso Del (1985). O Rio de Janeiro de Pereira Passos. Uma cidade em questão II. Rio de Janeiro: Index.

CARVALHO, Vânia Carneiro de; LIMA, Solange Ferraz de (1997). Fotografia e cidade: da razão urbana à lógica do consumo. Álbuns de São Paulo (1887-1954). São Paulo, Mercado de Letras.

DUBOIS, Philippe (1993). O ato fotográfico e outros ensaios. Campinas: Papirus. ENTLER, Ronaldo; OLIVEIRA Jr., Ronaldo (2003). "Rio de mão dupla: dois olhares sobre a metrópole". In: Facom. no. 11. São Paulo: Faculdade de comunicação da FAAP. Disponível em http://www.faap.br/ Acesso em 28 de novembro de 2013.

FABRIS, Annateresa (1991). "A invenção da fotografia: repercussões sociais". In: FABRIS. (org.) Fotografia: usos e funções no século XIX. São Paulo: EDUSP.

FABRIS, Annateresa (2000). Fragmentos urbanos: representações culturais. São Paulo: Studio Nobel.

FERREZ, Marc (1983). O álbum da Avenida Central. Um documento fotográfico da construção da Avenida Rio Branco, Rio de Janeiro, 1903-1906. São Paulo: João Fortes Engenharia \& Editora Ex-Libris.

FERREZ, Gilberto (1983). "A Avenida Central e seu Álbum". In: FERREZ, Marc. o álbum da Avenida Central. Um documento fotográfico da construção da Avenida Rio Branco, Rio de Janeiro, 1903-1906. São Paulo: João Fortes Engenharia \& Editora Ex-Libris.

KOK, Glória (2005). Rio de Janeiro na época da Avenida Central. São Paulo: Bei Comunicação. Disponível em http://www.aprendario.com.br/rj_livro.asp. Acesso em 29 de janeiro de 2014.

URBANA, V.6, no 9, ago-dez, 2014 - Dossiê: Dimensões Simbólicas das Intervenções Urbanas CIEC/UNICAMP 
KOSSOY, Boris (2002). Realidades e ficções na trama fotográfica. São Paulo: Ateliê Editorial.

LIERNUR, Jorge F (1992). "La ciudad efímera". In: LIERNUR, Jorge F. \& SILVESTRI, Graciela. El umbral de la metrópolis: transformaciones técnicas y cultura en la modernización de Buenos Aires (1870-1930). Buenos Aires: Sudamericana.

LIMA, Solange Ferraz de. CARVALHO, Lima e Vânia Carneiro de (1997). Fotografia e cidade: da razão urbana à lógica do consumo. Álbuns de São Paulo (1887-1954). São Paulo: Mercado de Letras.

MONTEIRO, Charles (2012). "Imagens da cidade de Porto Alegre nos anos 1950: a elaboração de um novo padrão de visualidade urbana nas fotorreportagens da Revista do Globo". In: Fotografia, história e cultura visual: pesquisas recentes. Porto Alegre: EDIPUCRS.

NEEDEL, Jeffrey (1993). Belle époque tropical: sociedade e cultura de elite no Rio de Janeiro na virada do século. São Paulo: Companhia das Letras.

PESAVENTO, Sandra Jatahy (1995). "Muito além do espaço: por uma história cultural do urbano". In: Estudos Históricos. Rio de Janeiro, vol. 08, no 16.

POSSAMAI, Zita Rosane (2007). "Narrativas fotográficas sobre a cidade". In: Revista Brasileira de História, v. 27.

ROULLÉ, André (2009). A fotografia: entre documento e arte contemporânea. São Paulo: Ed. SENAC.

SONTAG, Susan (2004). Sobre fotografia. São Paulo: Companhia das Letras.

TURAZZI, Maria Inez (2004). "Fotografias de uma cidade moderna". In: Rio de Janeiro - Buenos Aires, duas cidades modernas. Fotografias 1900-1930. Rio de Janeiro: BNDES e Buenos Aires: BICE.

TURAZZI, Maria Inez (2006). "Paisagem construída: fotografia e memória dos 'melhoramentos urbanos' na cidade do Rio de Janeiro". In: Varia História. Belo Horizonte, vol. 22, no 35 .

URBANA, V.6, no 9, ago-dez, 2014 - Dossiê: Dimensões Simbólicas das Intervenções Urbanas CIEC/UNICAMP 